\title{
Concepções de Profissionais de Saúde Mental acerca de Atividades Terapêuticas em CAPS
}

\author{
Teresinha Cid Constantinidis ${ }^{1, ~ *}$ \\ Orcid.org/0000-0001-9712-3362 \\ Maria Fernanda Barboza Cid $^{2}$ \\ Orcid.org/0000-0002-0199-0670 \\ Lenise Moraes Santana ${ }^{1}$ \\ Orcid.org/0000-0002-0169-3828 \\ Suzana Rodrigues Renó ${ }^{1}$ \\ Orcid.org/0000-0002-3279-092X
}

${ }^{1}$ Universidade Federal do Espírito Santo, Vitória, ES, Brasil

${ }^{2}$ Universidade Federal de São Carlos, São Carlos, SP, Brasil

\begin{abstract}
Resumo
Trata-se de pesquisa qualitativa de delineamento exploratório sobre as concepções de profissionais de saúde mental acerca da utilização de atividades terapêuticas em suas práticas em centros de atenção psicossocial (CAPS). Compreender os saberes que subjetivam a utilização da atividade terapêutica tem importância primordial na avaliação dos serviços e na construção de novos modelos de produção de atenção e cuidado em saúde mental. Foram realizados três grupos focais com profissionais de três CAPS de cidade de região sudeste do país. A análise dos dados foi feita através análise de conteúdo de modalidade temática. A análise articulada com o referencial teórico concernente ao paradigma das práticas em saúde mental apontou que os profissionais reconhecem as atividades realizadas em uma clínica descentrada do sintoma e da medicalização do transtorno mental, como forma de acolhimento, centrada no processo terapêutico, porém com poucas menções às ações concretas no território e integração comunitária das pessoas com transtorno mental.
\end{abstract}

Palavras-chave: Atividade terapêutica, desinstitucionalização, produção de cuidado em saúde mental.

\section{Conceptions of Mental Health Professionals about the Therapeutic Activity in the CAPS}

\begin{abstract}
This is a qualitative research of exploratory design on the conceptions of mental health professionals about the use of therapeutic activities in their practices in psychosocial care centers (CAPS). Understanding the knowledge that subjects the use of therapeutic activity is of paramount importance in the evaluation of services and in the construction of new models of mental health. Three focal groups were held with

* Endereço para correspondência: Universidade Federal do Espírito Santo, Programa de Pós Graduação em Psicologia, Av. Fernando Ferrari, s/n, Vitória, ES, Brasil 29055-350. E-mail: teracidc@gmail.com
\end{abstract}


professionals from three CAPS cities in the southeast region of the country. The analysis of the data was done through content analysis of thematic modality. The articulated analysis with the theoretical reference concerning the paradigm of the practices in mental health pointed out that the professionals recognize the activities carried out in a decentred clinic of the symptom and the medicalization of the mental disorder, as a form of reception, centered in the therapeutic process, but with few mentions Concrete actions in the territory and community integration of people with mental disorders.

Keywords: Therapeutic activity, deinstitutionalization, care production in mental health.

\section{Concepciones de los Profesionales de Salud Mental acerca de la Actividad Terapéutica en CAPS}

\section{Resumen}

Se trata de una investigación cualitativa en los conceptos de los profesionales de la salud mental acerca del uso de actividades terapéuticas en sus prácticas. Conocer el el uso de la actividad terapéutica es de primordial importancia en la evaluación de las acciones y en la construcción de nuevos modelos de atención y cuidado en salud mental. Tres grupos focales se realizaron con profesionales de CAPS en sureste del Brasil Se realizó el análisis de datos utilizando de la modalidad temática en análisis de contenido. El análisis articulado con el marco teórico en torno al paradigma de las prácticas de salud mental se encontró que los profesionales reconocen las actividades llevadas a cabo descentrada de la medicalización de trastorno mental como una forma de recepción, centrada en el proceso terapéutico, sin embargo con pocas referencias a acciones concretas sobre el territorio y la comunidad en relacion a la integración de las personas con trastorno mental.

Palabras clave: Actividad terapéutica, desinstitucionalización, producción de cuidado en salud mental.

A Reforma Psiquiátrica, que envolveu o processo de transformação do cuidado ofertado às pessoas com sofrimento psíquico intenso, permitiu avanços nas formas de compreender a experiência do sofrimento e especialmente no desenvolvimento de novas estratégias de assistência a essa população. Dentre tais avanços, a utilização de atividades como parte do processo de tratamento, sofreu modificações acompanhadas pela proposição de novas abordagens clínicas, institucionais e sociais para o sofrimento psíquico. A realização de atividades pelos usuários passa a ter o objetivo de desfazer a segregação, favorecer o aprendizado e a participação social, diferente da proposta anterior à reforma que, gestada no Tratamento Moral e respondendo a uma lógica manicomial de controle do tempo e da mente dos internos, defendia a realização de atividades, na recondução a um papel socialmente aceito para essas pessoas (Amarante, 2014).

No Brasil, influenciado principalmente pelo movimento de desinstitucionalização italiana, inicia-se o processo que se convencionou a ser chamado de "Reforma Psiquiátrica Brasileira" que culminou em 2001 com a sanção da "Lei da Reforma Psiquiátrica" - Lei 10.216. Esse movimento traz a Reabilitação psicossocial como novo modelo de atenção em saúde mental. Por meio desse modelo, busca-se facilitar a reestruturação da autonomia e possibilitar maior participação social da pessoa com sofrimento psíquico na comunidade. A participação social é a conquista o lugar de sujeito político do louco, processo que passa a contar com o que vem sendo denominado de protagonismo do sujeito (Torre \& Amarante, 2001). Esse protagonismo envolve a participação ativa desse sujeito e interferência no campo político, no debate sobre seu tratamento. Essa pessoa protagonista sai do lugar do paciente, do alienado, do tutelado e passa para o lugar de participante ativo, autônomo, que decide/negocia com seu meio social. Dessa forma, a Reabilitação psicossocial traz uma perspectiva de intervenção que rompe com as psi- 
coterapias tradicionais, do sujeito isolado, mas volta-se para o sujeito social, entendido em uma perspectiva relacional, em que é considerada sua inserção na cultura e redes sociais. Para isso,

. . . é necessário adotar um modelo de saúde humanizado que considere o cuidado integral e a ativa participação de todos, principalmente a dos próprios usuários, na elaboração e condução dos seus projetos terapêuticos, fortalecendo o "protagonismo social", no sentido de desenvolver autonomia e autodeterminação. (Sistema Único de Saúde, 2010, p. 63)

Nesse sentido, Rotelli (2001) aponta para o trabalho terapêutico voltado para a produção da vida, ou seja, considerar intervenções voltadas para a reconstrução das pessoas institucionalizadas como doentes mentais no sentido de potencializá-las como atores sociais, impedindo a anulação desses sujeitos sob a máscara da doença. "Que tratar signifique ocupar-se aqui e agora para que se transformem os modos de viver e sentir o sofrimento do paciente e que ao mesmo tempo se transforme a sua vida concreta cotidiana" (p. 76).

Assim, as ações passam a ser norteadas por outros referenciais que fazem forte contraposição ao tratamento moral e a todas as modalidades de ocupação do tempo ocioso, indo além das atividades meramente ocupacionais. A realização de atividades passa a ser pensada a partir de sua repercussão sobre a realidade concreta do sujeito, criando estratégias inclusivas, focalizando na participação social, ampliando as possibilidades de trocas com a vida pública, assumindo um caráter clínico e político (Guerra, 2004).

Nos serviços substitutivos ao modelo manicomial, como os centros de Atenção Psicossocial (CAPS), as atividades terapêuticas constituem-se nas principais tecnologias de cuidado (Tavares, Barone, Fernandes, \& Moniz, 2003) e estão voltadas para a integração do usuário e de sua família na sociedade, a partir da perspectiva comunitária. Os relacionamentos afetivos, sociais, familiares e comunitários da pessoa com sofrimento psíquico passam a ocupar o primeiro plano nas ações desses serviços (Azevedo \& Miranda, 2011).
Kantorski et al. (2011), em estudo integrante de pesquisa de avaliação dos CAPS da Região Sul do Brasil identificam as contribuições dos suportes terapêuticos desenvolvidos em tais instituições e apontam que para que haja inserção social da pessoa com sofrimento psíquico é importante a oferta de espaços que garantam o desenvolvimento das potencialidades desse sujeito e sugerem a inclusão de atividades no projeto terapêutico oferecido pelos serviços. Segundo estudo dessas autoras, as atividades desenvolvidas no CAPS podem funcionar de maneira que os usuários possam reconquistar ou conquistar seu cotidiano, de desenvolver habilidades laborativas, de independência e de possibilidades de liberdade e autonomia. Nessa direção, um dos espaços para a realização de atividades, nesses serviços substitutivos, é a oficina terapêutica:

Essas oficinas são atividades realizadas em grupo com a presença e orientação de um ou mais profissionais, monitores e/ou estagiários. Tais atividades podem ser definidas através do interesse dos usuários, das possibilidades dos técnicos do serviço, das necessidades, tendo em vista a maior integração social e familiar, a manifestação de sentimentos e problemas, o desenvolvimento de habilidades corporais, a realização de atividades produtivas, o exercício coletivo da cidadania. (Ministério da Saúde, 2004)

De acordo com Azevedo e Miranda (2011) as oficinas apontam para o entrelaçamento entre subjetividade e cidadania, isto é, entrelaçamento das dimensões psíquicas e políticas do sujeito e podem ser consideradas terapêuticas quando possibilitam um espaço de fala, expressão e acolhimento, podendo favorecer o processo de inserção social do sujeito. É importante salientar que as atividades terapêuticas fazem parte de diferentes modalidades de atenção e cuidado em saúde mental, não se limitando às oficinas terapêuticas. As atividades terapêuticas podem estar presentes em atendimentos individuais, em grupos terapêuticos de diferentes abordagens (grupos de terapia ocupacional, psicodrama, etc.) em atividades de acompanhamento terapêutico (AT), dentre outras. No entanto, na produção científica nacional, as atividades terapêuticas 
utilizadas nos serviços de saúde mental são realizadas principalmente no âmbito das oficinas (Azevedo \& Miranda, 2011; Soares \& Reinaldo, 2010).

Estudos nacionais buscam situar as oficinas como dispositivo grupal no processo de produção de cuidado (Benevides, Pinto, Cavalcante, \& Jorge, 2010; Jucá, Medrado, Safira, Gomes, \& Nascimento, 2010), como instrumento clínico-político exitoso no processo de desisntitucionalização da loucura (Oliveira \& Passos, 2007; Pádua \& Salum, 2010).

Além desses, encontram-se estudos como o de Lussi e Shiramizo (2013) que exploram a oficina como recurso de produção e troca de mercadorias e de afetos por meio das oficinas de geração de trabalho e renda. Esse tipo de oficina é prevista pela atual política de Saúde Mental, na implantação da Rede de Atenção Psicossocial - RAPS (Portaria n. 3.088, 2011), que propõe a ampliação dessas oficinas e estratégias intersetoriais de geração de renda como as cooperativas sociais. As oficinas, portanto, não são utilizadas simplesmente como instrumento terapêutico, mas vão além dos limites institucionais, com inserção no território. Na literatura internacional, entretanto, encontram-se estudos em que as atividades terapêuticas são exploradas fora de atividades grupais, como atividades de reabilitação realizada junto à comunidade, com a proposta de treinamento de habilidades relacionadas às atividades da vida diária e interação social (Saraceno, 2007; Test \& Stein, 2000). Nesta perspectiva, os estudos tanto nacionais como internacionais, independente da metodologia, trazem as atividades terapêuticas como possibilidade de invenções de novas formas de vida, de novas maneiras de lidar com as situações que as pessoas se deparam, com seus sintomas, com suas doenças, com suas relações. No entanto, a despeito de apontarem a importância e amplitude psicossocial das atividades terapêuticas, trazem de forma quase unânime a importância da reflexão crítica do trabalho que está sendo realizado pelos profissionais de saúde mental na condução desses dispositivos, evitando que se caia nas armadilhas da psiquiatria segregadora.
As instituições psiquiátricas funcionam com base no paradigma racionalista da ciência moderna, valorizam a relação problema-solução, processo pelo qual liga diagnóstico a prognóstico, que conduz da doença à cura (Rotelli, 2001). Considerando que desinstitucionalização é um trabalho prático de transformação do modo como as pessoas são tratadas, a solução-cura deixa de ser alvo na atenção e cuidado à pessoa com sofrimento psíquico e é colocado em seu lugar um conjunto complexo e cotidiano de estratégias que realizam a passagem da cura para a produção de vida. O processo de cuidado referido considera os sujeitos como protagonistas. Nessa direção, a realização de atividades integra um projeto de emancipação do sujeito, sem visar a retirada de sintomas e/ou a eliminação da crise (concebida de maneira médica), mas como estratégia de conferir protagonismo aos sujeitos, respeitando a singularidade das pessoas (Constantinidis \& Cunha, 2016).

Lima (2004) questiona sobre a diferença entre as práticas contemporâneas no uso de atividades em saúde mental e o tratamento moral. Para a autora, apesar das práticas com atividades serem herdeiras do tratamento moral, é preciso fazer uma inversão de sentido, problematizando-as, de forma a não naturalizá-las. Essa seria a condição apontada pela autora para desfazer "essa naturalização que, muitas vezes, tem como efeito, a manutenção de lógicas alienantes vestidas de inovadoras e o enfraquecimento da potência disruptiva e inventiva das atividades" (Lima, 2004, p. 32).

Nessa linha de discussão, Bezerra (2007) aponta que lutar contra o esmaecimento da política, e a hegemonia crescente do discurso técnico, não significa apenas ter o entendimento e a colocação em prática das políticas e modelos propostos. Para o autor, significa buscar entre os profissionais combater os "manicômios mentais" (Pelbart, 1991) - resistentes às mudanças por estarem enraizados em padrões cognitivos e afetivos profundamente internalizados.

Nesse sentido, estudo de Fiorati e Saeki (2012) aponta que, apesar dos avanços na área, encontram-se profissionais de saúde mental cujo trabalho se caracteriza pela extrema tecnificação 
das ações terapêuticas que enfatizam o tratamento clínico-medicamentoso. Como resultado, as ações psicossociais ficam para segundo plano, com o fechamento do trabalho nos serviços e a não inclusão social do usuário. Segundo as autoras, as mudanças na infraestrutura do manicômio - com a introdução de trabalho em grupo e oficinas terapêuticas diversas -, com as mudanças legais no cenário da psiquiatria/saúde mental não foram o bastante. Para Azevedo e Miranda (2011), é importante haver investimento dos profissionais de saúde mental para que haja mudanças na lógica psiquiatrizante e na forma de atenção e cuidado, tornando-as comunitárias. Apontam que é necessário o engajamento na construção de novas relações entre serviço e comunidade, criando redes sociais de apoio ao sujeito, com serviço de base territorial, buscando instrumentalizar a comunidade em relação às respostas outras ao sofrimento psíquico. Para isso, as atividades terapêuticas têm que expandir-se para além dos limites e espaços físicos das instituições e ganhar os espaços comunitários e do território existencial das pessoas.

Neste cenário, refletir sobre o lugar da prática em saúde mental, sobre os saberes que subjetivam, que sustentam a possibilidade de ação do profissional de saúde mental tem importância primordial, na medida em que a maneira como essa prática acontece traz consigo as representações que sustentam a utilização das atividades terapêuticas.

O presente estudo, portanto, busca avançar nestas reflexões, na medida em que pretende favorecer a emersão de novos elementos a partir da compreensão dos próprios profissionais de saúde mental sobre o desenvolvimento de atividades terapêuticas em sua prática cotidiana nos serviços substitutivos de saúde mental. Acredita-se que estudos desta natureza são importantes pois contribuem para o maior entendimento sobre o que tem sido praticado na atenção psicossocial, levantando novas questões a serem investigadas em estudos posteriores e fornecendo subsídios para o planejamento e implementação de práticas mais efetivas em saúde mental.

Assim, o objetivo desta pesquisa foi compreender as concepções de profissionais de saú- de mental acerca da utilização de atividades terapêuticas em suas práticas em centros de atenção psicossocial (CAPS).

\section{Método}

Partindo da proposta de entender quais os significados que profissionais de saúde mental associam à atividade terapêutica na prática de cuidado em saúde mental, o método qualitativo mostrou-se o mais adequado.

\section{Participantes}

Participaram da pesquisa, 21 profissionais de saúde mental que prestam assistência em três Centros de Atenção Psicossocial (CAPS) de uma cidade de grande porte, situada no sudeste do país. Dois desses CAPS são da modalidade CAPS III e um desses da modalidade CAPS i II.

Diante dos objetivos do estudo, a utilização de atividades terapêuticas em suas práticas, foi o único critério de seleção dos participantes. Cumpriam esse requisito e concordaram em participar da pesquisa: duas assistentes sociais, duas arteterapeutas, dois enfermeiros, um médico, três musicoterapeutas, seis psicólogos e cinco terapeutas ocupacionais. Foram excluídos profissionais de saúde mental que declararam não utilizar-se de atividades terapêuticas em suas práticas de atenção e cuidado em saúde mental.

O tempo de prática de trabalho em saúde mental dos profissionais participantes não foi considerado como critério de escolha dos participantes, porém, verificou-se que a variação de três a vinte anos de trabalho nessa área. Nota-se que a experiência profissional na área é variável, considerando-se positivo diante dos objetivos do estudo.

\section{Instrumento}

Para coleta de dados buscou-se um instrumento que possibilitasse a reflexão do grupo de profissionais a respeito da utilização de atividades terapêuticas em suas práticas e a expressão de suas representações e percepções sobre o assunto. Para dar conta desta tarefa, o grupo focal, que se apoia na interação entre seus participantes 
a partir de tópicos que são colocados para discussão mostrou-se ser o meio adequado para alcançar os dados desejados. Este instrumento parte da tendência humana de formar opiniões e atitudes na interação com outros indivíduos. $\mathrm{O}$ esforço combinado dos integrantes de um grupo focal, na elaboração das questões colocadas, produz mais informações e com maior riqueza de detalhes do que o somatório das respostas individuais (Dias, 2000).

\section{Procedimentos de Coleta de Dados}

Foi escolhido o CAPS por ser um dispositivo estratégico em saúde mental, um serviço de saúde aberto, comunitário, que oferece atendimento diário às pessoas com transtornos mentais severos e persistentes realizando o acompanhamento clínico e a reinserção social dessa pessoa (Ministério da Saúde, 2004). Utiliza em suas estratégias de atenção e cuidado, dentre outras, as atividades que aparecem como valiosos recursos na reabilitação psicossocial (Kantorski et al., 2011; Lima, 2004).

Inicialmente as pesquisadoras apresentaram o projeto de pesquisa e seus objetivos aos profissionais dos três CAPS nas reuniões de equipe, abrindo-se espaço para discussão do projeto e esclarecimento de possíveis dúvidas. Feito isso, de acordo com as disponibilidades de agenda dos profissionais, chegou-se a uma data e horário comuns em que foi marcada a realização do grupo focal.

Em cada CAPS foi realizado um único grupo em uma única sessão, com duração média de 90 minutos. A pesquisa totalizou três grupos focais, portanto, com média de sete participantes em cada grupo. Cada sessão de grupo focal foi moderada por dupla de pesquisadoras, previamente treinadas na técnica. Os tópicos que nortearam a discussão nos grupos focais foram: cotidiano de trabalho no CAPS, relação que profissionais estabelecem com a atividade/ ocupação em suas práticas de assistência em saúde mental, vantagens e desvantagens do uso de atividades terapêuticas nas ações em saúde mental. As sessões foram gravadas em arquivos digitais de áudio e posteriormente transcritas e analisadas.

\section{Procedimentos de Análise de Dados}

O tratamento do material, a sua codificação, se deu por intermédio da análise de conteúdo descrita por Bardin (1979). A proposta da pesquisa foi fazer a discussão/interpretação dos dados coletados no grupo focal e a escolha por esse procedimento de tratamento/análise se deu por permitir discutir/inferir a partir dos dados trabalhados. Essa pesquisa foi trabalhada na modalidade de análise temática que "procura nas expressões verbais ou textuais os temas gerais recorrentes que fazem a sua aparição no interior de vários conteúdos mais concretos" (Turato, 2008, p. 442).

A transcrição dos dados advindos dos grupos focais foi feita pelas pesquisadoras e foi parte de uma primeira leitura do material. Depois desta, houve várias outras leituras, no sentido de "ruminar os dados", de deixar-se "invadir por impressões e orientações" (Bardin, 1979, p. 40). A partir das informações que emergiram dos resultados, foi feita analise a partir do referencial concernente ao paradigma das práticas em saúde mental, mais especificamente, da desinstitucionalização.

\section{Procedimentos Éticos}

Tendo em vista a população estudada, na realização da coleta de dados foram seguidas as diretrizes e normas para pesquisas envolvendo seres humanos, do Conselho Nacional de Saúde. O projeto foi aprovado pelo Comitê de Ética em Pesquisa (CEP) do Centro de Ciências da Saúde (CCS) da Universidade Federal do Espírito Santo (UFES), com parecer n. 4821/ 2009.

Para manter o anonimato dos participantes na apresentação dos trechos dos relatos, na seção de resultados, os nomes dos profissionais foram omitidos e substituídos pela letra $\mathrm{P}$. Os números correspondem à identificação numérica de cada participante.

\section{Resultados e Discussão}

Os dados analisados apontaram regularidades discursivas que delinearam quatro categorias temáticas, a saber: (a) Atividade e acolhimento; (b) Atividade e a relação terapêutica; (c) Ati- 
vidade: produto ou processo; (d) Atividade e o contexto psicossocial, que serão apresentadas na tabela a seguir.

Tabela1

Resultados

Categorias Subcategorias Recortes de relatos de participantes

Atividade e Espaço de continência

. . ela vem pra cá, totalmente atordoada, massacrada, chega aqui e acolhimento Comunicação não verbal existe um espaço enorme pra ela, a gente só abriu espaço pra ela fazer Expressão de necessidades coisas que talvez ela tivesse um..., que ninguém soube, entendeu? Nós Espaço de inclusão
Atividade e relação terapêutica
Atividade mediadora da relação Campo de ação do profissional, do estar com, acompanhar Horizontalidade $\mathrm{x}$ verticalidade na relação
Atividade: produto ou processo?
Cobrança institucional por produções materiais/ concretas.

Profissionais ativos e usuários espectadores do processo.

Importância do processo em detrimento da materialidade da produção.
Na Tabela 1 são apresentadas esquematicamente e ilustrativamente, as categorias, as subcategorias e os relatos significativos que emergiram deste estudo. Observa-se que as análises e discussões serão apresentadas nas seções abaixo. abrimos o espaço, abrimos os braços pra ela, e ela hoje está feliz da vida, chegou aqui sem falar, hoje fala, tudo o que ela quer.. (P2)

... a princípio você vai observar qual é a necessidade dele, o que ele gosta, vai ver qual é a característica dele, qual a necessidade, mas isso ai não é uma coisa assim fixa não, a gente tem observado que é dinâmico, a própria atividade assim de oficina ou coletivo, isso ai é dinâmico, em algumas ocasiões surgiram, é, vamos dizer, oficinas novas diante do desejo... (P4)

Aqui a gente não trabalha, né, colocando o autista diferente ou separado de todos os outros pacientes, ele tá inserido nas brincadeiras, nos jogos, nas atividades, né, ele tá no espaço coletivo, ele tá junto com os outros, na medida do possível, na medida das possibilidades dele. $(\mathrm{P} 1)$

Quando a gente fala de oficina, né, que isso tudo é a pessoa, é o mediador, é a atividade, existe uma relação, está havendo um contrato, tá havendo uma vinculação, inclusive entrando uma atividade e existe uma aposta de ambas as partes de uma melhora. Eu acho que envolve uma clínica onde o trabalho no ofício é interagir . . . a relação é que é terapêutica ou não é terapêutica. (P7)

Se esse usuário, não se envolve com o profissional e o profissional não se envolve como usuário não vai acontecer a oficina, não vai existir esse meio, esse tratamento não vai estar completo. Eu penso no profissional como um... acompanhamento. (P3)

$A$ atividade no tratamento é supervisionada por profissional que tá ali com um objetivo . . . a intervenção terapêutica visa a melhora do indivíduo, ... ter ganhos que você vai monitorar, vai acompanhar os ganhos ou não, e vai modificando aquele tratamento. (P1)

"E ele trabalha não é construindo alguma coisa concreta, mas ele é nele né? Tipo: Ah, ele fez oficina, fez o que então? Qual é o... Fez caixinha? Entendeu? Você até pode fazer, mas isso não é a finalidade!" (P11).

"Alguns profissionais deixam os desenhos prontos, só para os pacientes pintarem para ter um trabalho bonito" (P8).

"Os produtos que eu construo com os pacientes, . . . não têm esse enfoque: pra mostrar. . . Não têm esse objetivo. Às vezes ele amassa tudo e joga na lata do lixo" (P9).

"O Processo é positivo não só quando o paciente aprende a fazer a atividade ou tem um produto final. Positivo é essa trajetória toda e o reflexo na vida do paciente" (P5). 
Atividade Tratamento/cura como e contexto centralidade das ações. psicossocial Treinamento de habilidades sociais Inserção no território?
“. . . de certa maneira, quando a gente vê a pessoa que não faz atividades, que são de certa forma corriqueiras, a gente diz que é disfuncional..." (P6).

. . . passa por algo também de inclusão ou vir de inserção no contato com outras pessoas, né, então, quando você coloca grupos e oficinas nos CAPS, me chama a atenção que são dispositivos que nós temos, usamos para tratar. (P7)

. . quando os pacientes retornarem eles vão simular frustações, com esse aprendizado que a gente deu, de chegar lá e não ter, então, como é que eu me coloquei diante dessa frustação? Foi um aprendizado né.? (P8)

A gente trabalha com o paciente e sua familia buscando uma inserção no seu território. O tratamento nem é feito aqui, mas a gente acompanha o caso, procura parceiros como a UBS, a familia, recursos na comunidade, o próprio paciente, tentando um vínculo, tentando uma abertura e adesão . . como dispositivo. (P1)

Eu acho super interessante isso: "lugar de doido". Eu tô aprendendo a ter esse olhar que ele [paciente] não venha pra cá e se coloque como: "futuramente eu vou estar assim". . . . Não, ele tem que não se ver nesse lugar de doido e nem nesse lugar CAPS como um fim. (P5)

\section{Resultados}

\section{Atividade e Acolhimento}

Para Teixeira (2001), o acolhimento é uma técnica de conversa em que são esclarecidas as necessidades do usuário e as possibilidades de satisfazê-las. $\mathrm{O}$ autor propõe encontro entre profissional e usuário, em uma prática que seja pensada como "acolhimento-diálogo", como uma "técnica de conversa". Londero (2010) aponta a impossibilidade de haver um modelo único de como acolher. Segundo Schmidt e Figueiredo (2009) acolher é um processo que depende dos recursos clínicos da equipe no atendimento, escuta, avaliação e discriminação das demandas. Scheibel e Hecker Ferreira (2012), destacam que acolhimento, não se restringe ao conceito tradicional de triagem.

Os participantes apontam que o acolhimento é feito na chegada do usuário ao serviço com objetivo de organização da demanda, mas também perpassa e é transversal ao processo de tratamento.

... a princípio você vai observar qual é a necessidade dele, o que ele gosta, vai ver qual é a característica dele, qual a necessidade, mas isso ai não é uma coisa assim fixa não, a gente tem observado que é dinâmico. (P4)

Pinho, Hernández e Kantorski (2010) destacam que o acolhimento se transforma no início, meio e fim de um processo de atenção e cuidado em saúde quando elevado à categoria de responsabilidade social com os problemas do outro, como um mecanismo de escuta e oferta de possibilidades ao mesmo tempo. Nesse sentido, observamos que a noção de acolhimento relatado pelos participantes alinha-se às propostas dos estudos citados. No entanto, os resultados apontam que o diálogo com o usuário, a conversa, próprio do processo de acolhimento se dá para além da comunicação verbal, trazendo um avanço em relação ao modelo de acolhimento discutido até aqui.

Os profissionais deste estudo buscam reconhecer, através da observação, para além das demandas explícitas, as necessidades destes usuários, dentro da dinâmica de realização de atividades terapêuticas no CAPS. Neste processo há uma negociação, mesmo que implícita, entre o que o profissional/serviço pode oferecer e o que o usuário deseja. $\mathrm{O}$ acolhimento se dá por meio das atividades terapêuticas, onde o novo pode emergir, a diferença que a loucura representa pode ali ser manifestada e acolhida. Segundo 
os participantes deste estudo as atividades terapêuticas no CAPS servem ao acolhimento dos usuários em sua dor e abertura de outras possibilidades relacionais:

. . ela vem pra cá, totalmente atordoada, massacrada, chega aqui e existe um espaço enorme pra ela, a gente só abriu espaço pra ela fazer coisas que talvez ela tivesse um..., que ninguém soube, entendeu? Nós abrimos o espaço, abrimos os braços pra ela, e ela hoje está feliz da vida, chegou aqui sem falar, hoje fala, tudo o que ela quer... (P2)

Os espaços do CAPS em que acontece a realização de atividades terapêuticas se caracterizam por seu potencial de continência às diferentes manifestações trazidas pelos usuários, conforme a fala de P15:

Aqui a gente não trabalha né, colocando o autista diferente ou separado de todos os outros pacientes, ele tá inserido nas brincadeiras, nos jogos, nas atividades, né, ele tá no espaço coletivo, ele tá junto com os outros, na medida do possível, na medida das possibilidades dele. (P15)

Neste sentido, podemos inferir que o acolhimento nestes espaços de realização de atividades, além de ser uma estratégia inclusiva, presente nos relatos dos profissionais, contribui para o processo de construção da cidadania das pessoas com sofrimento psíquico, objetivo do processo de desinstitucionalização. Representaria o avanço desse processo em espaço micropolítico, como no CAPS, nas oficinas, nos espaços coletivos em que realizam atividades em grupos ou em atividades individualizadas realizadas de acordo com o projeto terapêutico singular elaborado para cada usuário do serviço.

Estudos futuros que pudessem focalizar no impacto e avaliação do uso de atividades terapêuticas como estratégia utilizada pelos profissionais da saúde mental no processo de escuta e acolhimento das demandas dos usuários, sob a ótica de diferentes atores envolvidos (próprios usuários, familiares, profissionais) seria interessante na medida em que ampliaria a compreensão a respeito das dinâmicas de atenção adotadas nos CAPS e dos resultados que geram na vida dos usuários.

\section{Atividade e a Relação Terapêutica}

$\mathrm{Na}$ realização de atividades terapêuticas, de acordo com os relatos extraídos dos grupos focais, acontece o encontro entre usuário, atividade e profissional. Segundo os participantes, a atividade realizada nas diferentes ações do CAPS é mediadora da relação entre usuário e profissional, relação esta que se constituirá ou não em terapêutica, conforme os relatos de P7e P3:

Quando a gente fala de oficina, né, que isso tudo é a pessoa, é o mediador, é a atividade, existe uma relação, está havendo um contrato, tá havendo uma vinculação, inclusive entrando uma atividade e existe uma aposta de ambas as partes de uma melhora. Eu acho que envolve uma clínica onde o trabalho no oficio é interagir ... a relação é que é terapêutica ou não é terapêutica. (P7)

"Se esse usuário, não se envolve com o profissional e o profissional não se envolve com o usuário não vai acontecer a oficina, não vai existir esse meio, esse tratamento não vai estar completo" (P3).

Verifica-se que a relação entre profissional e usuário, com o contrato entre ambos, com a aposta na melhora do sofrimento psíquico, ocupa o primeiro plano na proposta terapêutica. A atividade é facilitadora deste processo. A relação é terapêutica, e não a atividade. Este achado vai ao encontro do que aponta Csordas (2008), para quem a perspectiva, a ênfase é colocada na relação estabelecida, e não na atividade em si. Assim, a simples realização de atividades não garante que o cuidado/tratamento aconteça. É preciso haver uma relação triádica: usuário-atividade-terapeuta.

Os participantes dividem-se quanto à posição do profissional na relação terapêutica, na realização de atividades. Para alguns, o profissional envolve-se e acompanha o usuário em seu fazer nos acontecimentos do CAPS, conforme ilustrado na fala abaixo:

Eu trago o elemento disparador. . . e de repente eu estou acompanhando e percebo que as coisas mudaram o rumo, lógico que existe o eixo, mas mudou o rumo porque dois ou três tão demonstrando, tão trazendo 
elementos que fazem a atividade se rearranjar né? (P9)

Para outros, o profissional está na posição de supervisor, de alguém que opera por meio de atividades em razão de circunstancias determinadas, como observado nas falas a seguir:

$A$ atividade no tratamento é supervisionada por profissional que tá ali com um objetivo . . . a intervenção terapêutica visa a melhora do individuo, ... ter ganhos que você vai monitorar, vai acompanhar os ganhos ou não, e vai modificando aquele tratamento. $(\mathrm{P} 1)$

"O profissional está ali na oficina, trabalhando com atividades terapêuticas no tratamento . . com um objetivo. O tratamento tem um objetivo, tem um resultado esperado que vou manejar e fazer acontecer" (P12).

A concepção do profissional que se envolve e acompanha traz um componente a mais a definição de Oficina do Ministério da Saúde, onde lê-se: "Essas oficinas são atividades realizadas em grupo com a presença e orientação [grifo nosso] de um ou mais profissionais, monitores e/ou estagiários" (Ministério da Saúde, 2004). A participação do profissional, nesta definição, limita-se à presença e orientação, não fazendo referência ao envolvimento do profissional neste processo. Acompanhar é fazer companhia a, ir em companhia de, tomar parte em ou seja, conforme o profissional está com o usuário na oficina, constituindo a horizontalidade na relação, desfazendo a assimetria constitutiva da relação inicial entre usuário que precisa de ajuda e profissional com o saber sobre o outro que presta atendimento (Constantinidis, 2011). Para Inojosa (2005), o que a atual política de saúde mental procura recuperar é "uma relação solidária entre sujeitos, um esforço consciente de trabalhar com as assimetrias, respeitando os saberes e poderes do outro" (p. 6).

No entanto, para alguns participantes, o profissional supervisiona as atividades e as maneja a partir de um objetivo pré-estabelecido que envolva a "melhora" do sujeito-alvo e que faz parte de seu processo de tratamento. Este resultado remete à reflexão a respeito da verticalidade na relação terapeuta-usuário, já discutida por alguns autores, como Vasconcellos e Azevedo (2010) que apontam a questão da detenção do "saber sobre" do profissional, que acaba configurando uma situação em que o profissional está acima do usuário. Neste sentido, o usuário assume posição passiva e consente, autoriza ao profissional a tomada de competência e a dizer o que é bom para ele. Os autores sinalizam, ainda, que esse tipo de relação foi questionada no movimento da reforma psiquiátrica, pois essa polarização pode dificultar a constituição de um campo intersubjetivo e participativo de cuidado (Vasconcellos \& Azevedo, 2010).

Vale observar que a partir deste achado do presente estudo não é possível caracterizar a relação terapeuta-usuário relatada como verticalizada e não foi objetivo aprofundar nessa dinâmica relacional. Além disso, o fato de o profissional planejar suas ações em função de objetivos pré-estabelecidos pode não necessariamente indicar a passividade do usuário neste processo. Assim, acredita-se que mais estudos que se debrucem sobre a dinâmica da relação terapeuta-usuário nos serviços de saúde mental, sob a luz do movimento da Reforma Psiquiátrica, considerando a complexidade da experiência do sofrimento psíquico, são importantes para a maior compreensão de como os profissionais de saúde mental tem desenvolvido seu trabalho e estabelecido suas relações na gestão do cuidado.

\section{Atividade: Produto ou Processo?}

Os participantes da pesquisa enfatizam o processo terapêutico que se dá na realização de atividades e aparece a preocupação da forma como o produto final pode ser referenciado na oficina: "Alguns profissionais deixam os desenhos prontos, só para os pacientes pintarem para ter um trabalho bonito" (P8). Em relação a isto, Delvano (2015) aponta que, na busca pelo produto final de valor social, alguns profissionais tomam a iniciativa de realização de qualquer que seja a atividade, enquanto que os usuários ocupam o lugar de expectadores ou consumidores das propostas.

Oliver, Tissi, Aoki, Vargem e Ferreira (2002) apontam que a valorização do produto final -sua estética, qualidade, utilidade- se dá pela 
exigência imposta pelo mercado de consumo. Kuntz (2016) aponta que o consumo se mostra intrinsicamente ligado à sociabilidade, à integração e ao pertencimento. Os profissionais participantes deste estudo, ao contrário da observação de Delvano (2015), desconsideram a potencialidade do produto final da realização das atividades e, atendo-se ao processo, ressaltam que a oficina tem como proposta a construção de algo sem ser território exclusivo de produção para exposição de habilidades ou para fins comerciais:

"Os produtos que eu construo com os pacientes, . . . não têm esse enfoque: pra mostrar . . . Não têm esse objetivo. Às vezes ele amassa tudo e joga na lata do lixo" (P9).

"É, às vezes se espera que tenha uma produção que possa ser mostrada, né? E ai não tem, pois o que importa é o processo que a pessoa tá passando, e não o que... o objeto final, né?" (P12).

"E ele trabalha não é construindo alguma coisa concreta, mas ele é nele né? Tipo: Ah, ele fez oficina, fez o que então? Qual é o... Fez caixinha? Entendeu? Você até pode fazer, mas isso não é a finalidade!" (P11).

Esses profissionais não visam apenas o produto concreto, feito pelos usuários, mas o que se produz no "entre" o começo - a entrada do sujeito na atividade, na confecção do objeto material - e o resultado final da proposta explícita da oficina. No "entre" da oficina está o fazer, as experimentações, as interações, a conquista do novo, a possibilidade de criar novas formas de ser e estar no mundo. Além disso, o relato de P5 aponta a importância do processo quando há repercussão na vida, na realidade concreta do sujeito.

“O Processo é positivo não só quando o paciente aprende a fazer a atividade ou tem um produto final. Positivo é essa trajetória toda e o reflexo na vida do paciente" (P5).

Os relatos apontam a uma centralidade do processo em detrimento do produto. No entanto, Guerra (2004) aponta que não podemos desconsiderar o fato de que a oficina sempre está referenciada a um produto final, à "materialidade do produto", segundo sua proposta explícita: oficina de pintura, oficina de jornal, oficina de culinária, etc. As oficinas produzem a apreensão do novo, a expressão de singularidades, inscrição da diferença da loucura na cultura e tudo que advém disso, por fundar-se na consigna de trabalhar sobre um objeto concreto. Seus efeitos subjetivos e socializantes são fundados na concretude dos materiais e na produção de algo. Além disso, apesar de o consumo não ser a única razão constituinte da vida social, a inscrição dessas experiências no mercado (produção e distribuição) propiciaria relações de trocas de outra dimensão, conforme destacam Oliver et al. (2002).

Assim, por um lado os profissionais mostram a priorização de um dos aspectos do fazer, fragmentação e oposição entre produto e processo na realização das atividades com preocupação em valorizar o sujeito e suas peculiaridades dentro de seu contexto de vida, a partir de relações significativas que possam ser originadas desse processo. Por outro lado, no entanto, desconsideram a inscrição social que o valor do produto como consumo traria. Segundo Oliver et al. (2002), tornar o produto final em consumo, com possibilidades de gerar renda, exige instrumentos ainda pouco sedimentados na prática dos profissionais da saúde.

\section{Atividade e o Contexto Psicossocial}

Apesar da proposta da atenção psicossocial, da reestruturação da atenção e cuidado à pessoa com sofrimento psíquico, na busca de um olhar sobre a pessoa que sofre e não sobre o desvio de um padrão classificatório, encontramos, no presente estudo, discursos que classificam comportamentos, a partir da realização de atividades, segundo uma funcionalidade padrão

“. . de certa maneira, quando a gente vê a pessoa que não faz atividades, que são de certa forma corriqueiras, a gente diz que é disfuncional..." (P6).

O discurso de P6 ilustra a posição de alguns profissionais que, apesar de posicionarem-se a favor da desinstitucionalização têm sua prática atrelada ao padrão de normalidade, trazendo o não envolvimento por parte do usuário, com aquilo que é oferecido a ele, como falha em relação a uma pretensa normalidade. Esse padrão classificatório faz parte do paradigma fundante 
das instituições psiquiátricas (Rotelli, 2001) e a incoerência entre o discurso e a prática dos profissionais trazem à tona os "manicômios mentais" (Pelbart, 1991).

Para alguns profissionais, a função das oficinas está relacionada a processos pedagógicos, onde é possível o treinamento de habilidades emocionais. Tais objetivos remetem a oficinas como reprodução de micro-sociedades, apropriadas para "simulações de processos" e ensinamentos, tendo como modelo implícito o tratamento moral.

“. . . quando os pacientes retornarem eles vão simular frustações, com esse aprendizado que a gente deu, de chegar lá e não ter, então, como é que eu me coloquei diante dessa frustação? Foi um aprendizado, né?" (P8).

Este resultado vai ao encontro do questionamento de Lima (2004) sobre a naturalização das práticas e a presença do tratamento moral, por trás de práticas inovadoras, que mantém a lógica alienante dos antigos manicômios, enfraquecendo a potência das atividades. Da mesma forma, as atividades terapêuticas podem ser demarcadas por métodos e técnicas de determinadas especialidades dos profissionais, perdendo-se a dimensão de um campo de competência em saúde mental sustentado pela intersecção de práticas interdisciplinares.

.. . pelo interesse do profissional, conforme as habilidades dele tanto pessoais como profissionais, fora o profissional, é formado em quê, atua com, têm habilidade e o interesse dele em trabalhar com aquilo que é do profissional dele de atuação ou não . . . eu acho que parte do profissional, de querer trabalhar com aquilo que é de atuação dele ou não . . . alguma coisa especifica, por exemplo, ninguém medica na equipe, só os psiquiatras que não têm disponibilidade para outras intervenções. (P19)

Este dado está em concordância com os estudos de Fiorati e Saketi (2012) e Zerbetto, Efigênio, dos Santos e Martins (2011), que apontam a tecnificação das práticas terapêuticas em saúde mental, a ênfase no tratamento clínico-medicamentoso, que colocam as ações psicossociais em segundo plano. Estudo de Galvanese, Nascimen- to e DOliveira (2013) mostra que o uso de atividades terapêuticas nos CAPSs está associada à concepção do "mito da atividade terapêutica" por reduzir o uso de atividades a remédio.

Até aqui os resultados indicam que grupos e oficinas terapêuticas realizadas no CAPS por um lado são vistos no sentido de dispositivo de tratamento, na perspectiva de incluir o usuário no tratamento no CAPS e por outro lado existe o entendimento da importância das atividades terapêuticas que, apesar de realizadas dentro da instituição, visam o território, com ações voltadas aos familiares e a comunidade.

A gente trabalha com o paciente e sua familia buscando uma inserção no seu território. O tratamento é feito aqui, [grifo nosso] mas a gente acompanha o caso, procura parceiros como a UBS, a família, recursos na comunidade, o próprio paciente, tentando um vínculo, tentando uma abertura e adesão . . . como dispositivo. $(\mathrm{P} 1)$

A fala de P1 aponta preocupação com as ações no território, em uma tendência psicossocial do cuidado, visando a totalidade do sujeito da atenção. Apesar da intenção explícita de ações territoriais, expressa por participantes deste estudo, os resultados indicam que a prática relatada mostra uma tendência estritamente clínica realizada dentro do CAPS. Para Onocko-Campos e Furtado (2006), o importante é preservar o vínculo com os usuários nas diversas fases de sofrimento. Para a autora, não se trata de negar ou abolir a clínica, mas de ampliá-la no sentido de responsabilizar-se pelas demandas concretas dos usuários. Não se trata de desconsiderar a clínica na atenção às pessoas com transtorno mental, mas de reafirmar o CAPS como dispositivo de atenção psicossocial a pessoas com transtorno mental grave e /ou persistentes, valorizando a tendência psicossocial caracterizada pela transversalidade entre clínica e ações territoriais. Assim, ações territoriais não se opõem a ações clínicas.

Em relação às ações serem realizadas dento do CAPS, este dado vai ao encontro dos resultados obtidos por Galvanese et al. (2013) em pesquisa sobre o processo de cuidado por meio de arte e cultura desenvolvida nos CAPS da cidade 
de São Paulo, em que das 126 atividades de arte e cultura, 96 foram desenvolvidas no interior dos CAPS, mostrando a tendência dos profissionais manterem suas ações dentro da instituição, com pouco aproveitamento dos espaços urbanos e do território.

Constantinidis e Cunha (2016) ressaltam a importância das atividades desenvolvidas nas oficinas, ou fora delas, contemplarem o território, entendido como espaço de atuação de toda a rede de serviços e de cidadãos que pertencem a ele. Para os autores, dessa forma haveria a articulação de serviços para reinventar a vida em todos os aspectos do cotidiano no qual a loucura foi privada de conviver.

\section{Considerações Finais}

O processo de desinstitucionalização não implica apenas o entendimento e a colocação em prática das políticas e modelos propostos, mas também a necessidade de reflexão por parte dos profissionais, sobre sua prática cotidiana de assistência à pessoa com transtorno mental. É importante que os profissionais reflitam sobre os pressupostos ideológicos e teórico-metodológico que embasam suas práticas no sentido de facilitarem as mudanças necessárias à desinstitucionalização. Sem a pretensão de esgotar as discussões sobre o tema, acreditamos que este estudo pode colaborar nesta reflexão.

Na utilização de atividades na atenção e cuidado à pessoa com transtorno mental, os profissionais reconhecem as atividades realizadas nas oficinas terapêuticas, como importante instrumento no acolhimento da pessoa com sofrimento psíquico, como catalisador da relação terapêutica, em uma clínica descentrada do sintoma e da medicalização do transtorno mental.

Nos relatos dos profissionais, percebe-se ainda a preponderância de atividades no interior do CAPS, com poucas menções às ações concretas no território. Na reabilitação psicossocial, há mudança de paradigma na atenção psiquiátrica, de modo a afirmar a autonomia do usuário, privilegiando o território e o cotidiano nas ações de cuidado. No entanto os profissionais, participantes deste estudo, não enfatizam a potência da atividade nas ações em saúde mental com a participação e integração comunitária das pessoas com transtorno mental. Assim, aponta-se a importância de estudos que apontem os fatores que possibilitem, impeçam e/ou dificultem a utilização de atividades nas ações dos profissionais de saúde mental no território, no espaço de vida das pessoas com sofrimento psíquico.

No sentido de avaliar e subsidiar práticas mais efetivas em saúde mental, este estudo abre discussão para futuras pesquisas sobre o ponto de vista de usuários e profissionais de saúde, sobre o impacto das diferentes modalidades de atividades terapêuticas na vida do usuário, principalmente no que se refere à vivência do sofrimento psíquico e à participação social.

\section{Referências}

Amarante, P. D. D. C. (2014). Saúde mental, desinstitucionalização e novas estratégias de cuidado. In S. Escorel, L. D. V. C. Lobato, J. C. D. Noronha, \& A. I. D. Carvalho (Eds.), Políticas e sistema de saúde no Brasil (pp. 635-655). Rio de Janeiro, RJ: Editora da Fundação Oswaldo Cruz.

Azevedo, D. M., \& Miranda, F. A. N. M. (2011). Oficinas terapêuticas como instrumento de reabilitação psicossocial: Percepção de familiares. Escola Anna Nery, 15(2), 339-345. doi: 10.1590/ S1414-81452011000200017

Bardin, L. (1979). Análise de Conteúdo. Lisboa: Edições 70.

Benevides, D. S., Pinto, A. G. A., Cavalcante, C. M., \& Jorge, M. S. B. (2010). Cuidado em saúde mental por meio de grupos terapêuticos de um hospital-dia: Perspectivas dos trabalhadores de saúde. Interface-Comunicação, Saúde, Educação, 14(32), 127-138. Recuperado em http:// www.scielosp.org/scielo.php?pid=S1414- 32832010000100011 \& script =sci_ abstract\&tlng=es

Bezerra, B., Jr. (2007). Desafios da reforma psiquiátrica no Brasil. Physis, 17(2). Recuperado em http://www.scielo.br/scielo.php?script=sci_ arttext\&pid=S0103-73312007000200002\&lng= en\&nrm=iso

Constantinidis, T. C. (2011). Familiares de pessoas com sofrimento psíquico e profissionais de saúde mental: Encontros e desencontros (Tese de dou- 
torado em Psicologia, Universidade Federal do Espírito Santo, Vitória, ES, Brasil). Recuperado em http://repositorio.ufes.br/handle/10/3128

Constantinidis, T. C., \& Cunha, A. C. (2016). Desinstitucionalizando conceitos: A terapia ocupacional em busca de um (novo) lugar no cenário da saúde mental. In T. S. Matsukura \& M. M. Salles (Eds.), Cotidiano, atividade humana e ocupação. Perspectivas da terapia ocupacional no campo da saúde mental (pp. 37-59). São Carlos, SP: Editora da Universidade Federal de São Carlos.

Csordas, T. (2008). Corpo/Significado/Cura. Porto Alegre, RS: Editora da Universidade Federal do Rio Grande do Sul.

Delvano, D. (2015). Artificios, narrativas e bricolagens: Efetua(ações) na clínica do oficinar (Dissertação de mestrado, Universidade Federal do Espírito Santo, Vitória, ES, Brasil). Recuperado em http://portais4.ufes.br/posgrad/teses/ tese_9150_Daniel\%20Delvano.pdf

Dias, C. A. (2000). Grupo focal: Técnica de coleta de dados em pesquisas qualitativas. Informação \& Sociedade: Estudos, 10(2), 67-72. Recuperado em http://bogliolo.eci.ufmg.br/downloads/ DIAS\%20Grupo\%20Focal.pdf

Fiorati, R. C., \& Saeki, T. (2012). As atividades terapêuticas em dois serviços extra-hospitalares de saúde mental: A inserção das ações psicossociais. Cadernos de Terapia Ocupacional UFSCar, 20(2), 207-215. doi: 10.4322/cto.2012.022

Galvanese, A. T. C., Nascimento, A. de F., \& DOliveira, A. F. P. L. (2013). Arte, cultura e cuidado nos centros de atenção psicossocial. Revista de Saúde Pública, 47(2), 360-367. doi: http://dx.doi. org/10.1590/S0034-8910.2013047003487

Guerra, A. M. C. (2004). Oficinas em saúde mental: Percurso de uma história, fundamentos de uma prática. In C. M. Costa \& A. C. Figueiredo (Eds.), Oficinas terapêuticas em saúde mental: Sujeito, produção e cidadania (pp. 23-58). Rio de Janeiro, RJ: Contra Capa.

Inojosa, R. M. (2005). Acolhimento: A qualificação do encontro entre profissionais de saúde e usuários. Trabalho apresentado no $X$ Congreso Internacional del CLAD sobre la Reforma del Estado y de la Administración Pública (pp. 1821). Santiago, Chile. Recuperado em http:// bresserpereira.org.br/Documents/MARE/OS/ inojosa_saude.pdf
Jucá, V. J. S., Medrado, A. C., Safira, L., Gomes, L. P. M., \& Nascimento, V. G. (2010). Atuação psicológica e dispositivos grupais nos centros de atenção psicossocial. Mental (Barbacena), 8(14), 93-113. Recuperado em http://pepsic.bvsalud. org/scielo.php?script=sci_arttext\&pid=S1679$-44272010000100006 \& \operatorname{lng}=$ pt\&nrm $=$ iso

Kantorski, L. P., Coimbra, V. C. C., de Aquino Demarco, D., Eslabão, A. D., Nunes, C. K., \& da Cruz Guedes, A. (2011). A importância das atividades de suporte terapêutico para o cuidado em um Centro de Atenção. Journal of Nursing and Health, 1(1) 4-13. Recuperado em https:// periodicos.ufpel.edu.br/ojs2/index.php/ enfermagem/article/view/3401/2792

Kuntz, F. M. R. (2016, 05-09 set.). O Consumo da Loucura: Um Ensaio Sobre a Loucura de Não Consumir. Trabalho apresentado no Intercom - Sociedade Brasileira de Estudos Interdisciplinares da Comunicação, XXXIX Congresso Brasileiro de Ciências da Comunicação. São Paulo, SP. Recuperado em http://portalintercom.org.br/anais/nacional2016/resumos/ R11-0773-1.pdf

Lei No. 10.216, de 6 de abril de 2001. (2001, 09 abr.). Dispõe sobre a proteção e os direitos das pessoas portadoras de transtornos mentais e redireciona o modelo assistencial em saúde mental. Diário Oficial da União. Recuperado em http://www. planalto.gov.br/ccivil_03/leis/leis_2001/110216. $\mathrm{htm}$

Lima, E. A. (2004). Oficinas, laboratórios, ateliês, grupos de atividades: Dispositivos para uma clínica atravessada pela criação. In C. M. Costa \& A. C. Figueiredo, Oficinas terapêuticas em saúde mental-sujeito, produção e cidadania (pp. 59-81). Rio de Janeiro, RJ: Contra Capa Livraria.

Londero, S. (2010). Re-inventando o acolhimento em um serviço de saúde mental (Dissertação de mestrado, Universidade Federal do Rio Grande do Sul, Porto Alegre, RS, Brasil). Recuperado em http://www.lume.ufrgs.br/ handle/10183/18872

Lussi, I. A. O., \& Shiramizo, C. S. (2013). Oficina integrada de geração de trabalho e renda: Estratégia para formação de empreendimento econômico solidário. Revista de Terapia Ocupacional da Universidade de São Paulo. 24(1), 28-37. doi: 10.11606/2238-6149.v24i1p28-37 
Ministério da Saúde. (2004). Legislação em saúde mental: 1990-2004. Brasília, DF: Autor.

Oliveira, J. A., \& M., Passos (2007). A implicação de serviços de saúde mental no processo de desinstitucionalização da loucura em Sergipe. Vivência (Natal), 1(1) 259-270. Recuperado em http://www.observasmjc.uff.br/psm/ uploads/A_implica\%C3\%A7\%C3\%A3o_de_ servi\%C3\%A7os_de_sa\%C3\%BAde_mental_ no_processo_de_desinstitucionaliza\%C3\%A7\% C3\%A3o_da_loucura_em_Sergipe_um_problema_cl\%C3\%ADnico-pol\%C3\%ADtico.pdf

Oliver, F. C., Tissi, M. C., Aoki, M., Vargem, E. de F., \& Ferreira, T. G. (2002). Oficinas de trabalho: Sociabilidade ou geração de renda? Revista de Terapia Ocupacional da Universidade de São Paulo, 13(3), 86-94. doi: http://dx.doi. org/10.11606/issn.2238-6149.v13i3p86-94

Onocko-Campos, R. T., \& Furtado, J. P. (2006). Entre a saúde coletiva e a saúde mental: Um instrumental metodológico para avaliação da rede de Centros de Atenção Psicossocial (CAPS) do Sistema Único de Saúde. Cadernos de Saúde Publica, 22(5), 1053-1062. doi: 10.1590/S0102$-311 \times 2006000500018$

Pádua, F. H. P., \& Salum, M. de L. (2010). Oficinas expressivas: Uma inclusão de singularidades. Psicologia USP, 21(2), 457-478. doi: 10.1590/S0103-65642010000200012

Pelbart, P. P. (1991). Manicômio mental: A outra face da clausura. In A. Lancetti (Ed.), Saúde e loucura: Vol. 2 (pp. 131-138). São Paulo, SP: Hucitec.

Pinho, L. B. D., Hernández, A. M. B., \& Kantorski, L. P. (2010). Serviços substitutivos de saúde mental e inclusão no território: Contradições e potencialidades. Ciência, Cuidado e Saúde, 9(1), 28-35. doi: http://dx.doi.org/10.4025/cienccuidsaude.v9i1.6824

Portaria n. 3.088 de 23 de dezembro de 2011. (2011). Institui a Rede de Atenção Psicossocial para pessoas com sofrimento ou transtorno mental e com necessidades decorrentes do uso de crack, álcool e outras drogas, no âmbito do Sistema Único de Saúde. Recuperado em http://www.brasilsus. com.br/legislacoes/gm/111276- 3088.html

Rotelli, F. (2001). A instituição inventada. In M. F. S Nicácio (Ed.), Desinstitucionalização (2. ed., pp. 89-99). São Paulo, SP:Hucitec.
Saraceno, B. (2007). New knowledge and new hope to people with emerging mental disorders. Early Intervention in Psychiatry, 1(1), 3-4. doi: 10.1111/j.1751-7893.2007.00001.x

Scheibel, A., \& Hecker Ferreira, L. (2012). Acolhimento no CAPS: Reflexões acerca da assistência em saúde mental. Revista Baiana de Saúde Pública, 35(4), 966. Recuperado em nseer.ibict. br/rbsp/index.php/rbsp/article/viewFile/266/ pdf_ 79

Schmidt, M. B., \& Figueiredo, A. C. (2009). Acesso, acolhimento e acompanhamento: Três desafios para o cotidiano da clínica em saúde mental. Revista Latinoamericana de Psicopatologia Fundamental, 12(1), 130-140. doi: 10.1590/S141547142009000100009

Sistema Único de Saúde. (2010, 27 jun.-01 jul.). Intersetorial. Relatório Final da IV Conferência Nacional de Saúde Mental - Intersetorial. Brasília, DF: Conselho Nacional de Saúde.

Soares, A. N., \& Reinaldo, A. M. S. (2010). Oficinas terapêuticas para hábitos de vida saudável: Um relato de experiência. Escola Anna Nery, 14(2), 391-398. doi: 10.1590/S141481452010000200025

Tavares, C. M. M., Barone, A. M., Fernandes, J. C., \& Moniz, M. A. (2003). Análise de implementação de tecnologias de cuidar em saúde mental na perspectiva da atenção psicossocial. Escola Anna Nery, 7(3), 342-350. Recuperado em http:// eean.edu.br/detalhe_artigo.asp?id=1055

Teixeira, R. R. (2001). Agenciamentos tecnosemiológicos e produção de subjetividade: contribuição para o debate sobre a trans-formação do sujeito na saúde. Ciência \& Saúde Coleti$v a, 6(1)$. Recuperado em http://www.scielosp. org/scielo.php?script $=$ sci_arttext\&pid $=\mathrm{S} 1413$ $81232001000100004 \& \operatorname{lng}=$ en $\& n r m=$ isso

Test, M. A., \& Stein, L. I. (2000). Practical guidelines for the community treatment of markedly impaierd patients. Community Mental Health Journal, 36(1), 47-60. Retrieved from http://search.proquest.com/openview/cb30162e0f57b6004246 b61e5ea5ee9a/1?pq-origsite=gscholar

Torre, E. H. G., \& Amarante, P. (2001). Protagonismo e subjetividade: A construção coletiva no campo da saúde mental. Ciência \& Saúde Coletiva, 6(1), 73-85. doi: http://dx.doi.org/10.1590/ S1413-81232001000100006 
Turato, E. R. (2008). Tratado da metodologia da pesquisa clínico-qualitativa. Petrópolis, RJ: Vozes.

Vasconcellos, V. C., \& Azevedo, C. S. (2010). The meanings of work and the organizational imaginary in a psychosocial care center (PCC). Interface-Comunicação, Saúde, Educação, 14(34), 563-576. Recuperado em www.scielo.br/pdf/ icse/v14n34/aop1010.pdf
Zerbetto, S. R., Efigênio, E. B., dos Santos, N. L. N., \& Martins, S. C. (2011). O trabalho em um Centro de Atenção Psicossocial: Dificuldades e facilidades da equipe de enfermagem. Revista Eletrônica de Enfermagem, 13(1), 99-109.

Recebido: $27 / 11 / 2016$

$1^{a}$ revisão: $26 / 03 / 2017$

Aceite final: $31 / 05 / 2017$

(cc)BY (C) O(s) autor(es), 2018. Acesso aberto. Este artigo está distribuído nos termos da Licença Internacional Creative Commons Atribuição 4.0 (http://creativecommons.org/licenses/by/4.0/), que permite o uso, distribuição e reprodução sem restrições em qualquer meio, desde que você dê crédito apropriado ao(s) autor(es) original(ais) e à fonte, fornecer um link para a licença Creative Commons e indicar se as alterações foram feitas. 